\title{
KARAKTERISTIK PEREMPUAN DALAM TAFSIR AYAT SUCI LENYEPANEUN KARYA MOH. E. HASIM
}

\author{
Nadia Laraswati, Syahrullah, Ahmad Gibson Al-Bustomi \\ Fakultas Ushuluddin UIN Sunan Gunung Djati Bandung \\ Jl.A.H.Nasution 105 Cibiru Bandung 40614, Indonesia \\ E-Mail : rifa.roifa@yahoo.com
}

\begin{abstract}
Abstrak
Budaya Sunda sebagai budaya lokal masyarakat Jawa Barat dipengaruhi adanya Islam, sebagai agama mayoritas etnis Sunda. Nilai budaya sunda masuk kedalam ragam kehidupan sosial budaya hasil dari adaptasi Islam dan budaya setempat. Hal ini menunjukkan kuatnya pengaruh budaya lokal dalam membentuk konstruksi identitas Islamicate Sunda. Terlihat dengan menyebarnya penerbitan-penerbitan tentang Islam di era modern yang bentuknya seperti tafsir Sunda beraksara Roman-Latin yang mulai dipublikasikan, khususnya tafsir Ayat Suci Lenyepaneun. Menarik dikaji untuk mengetahui bagaimana penafsiran terhadap karakteristik perempuan, karena kedudukan perempuan di masyarakat Arab dan di masyarakat Sunda tentu berbeda, maka sebarapa jauh pengaruh dari budaya Sunda terhadap penafsiran Alquran. Penelitian ini menggunakan deskripsi analisis untuk mengetahui karakteristik perempuan pada tafsir Ayat Suci Lelenyepaneun. Hasil penelitian ini menunjukkan karakter perempuan pada ayatayat Alquran, seperti: (1). QS. Al- Tahrim [66]: 11, (2). QS. Maryam [19]: 17-19, (3). QS. Al-Lahab [111]: 4-5, (4). QS. Al- Tahrim [66]: 10, (5). QS. Yūsuf[12]: 23 menunjukan lima karakter perempuan yaitu yaitu: (1) karakter perempuan dengan kepribadian kuat, (2) karakter perempuan yang menjaga kesuciannya, (3) karakter perempuan penghasut, (4) karater perempuan pembangkang kepada suaminya, dan (5) karakter perempuan penggoda.
\end{abstract}

Kata Kunci :

Budaya Sunda ; karakter perempuan ;tafsir ayat suci Leleunyapeun.

\begin{abstract}
Sundanese culture as a local culture of West Java society influenced the existence of Islam, as religion majority of Sundanese. The value of Sundanese culture enters into the diversity of social and cultural life resulting from the adaptation of Islam and local culture. Shows the strong influence of local culture in shaping the construction of the identity of Sunda Islamicate. This study uses descriptive analysis to determine the characteristics of women in the interpretation of the holy scripture Leleunyapeun. The results of this study show the female characters in the verses of the Qur'an, such as: (1). QS. Al- Tahrim [66]: 11, (2). QS. Maryam [19]: 17-19, (3). QS. al-Lahab [111]: 4-5, (4). QS. Al- Tahrim [66]: 10, (5). QS. Yüsuf [12]: 23 shows five female characters are: (1) female character with strong personality, (2) female character who keeps her holiness, (3) character of woman agitator, (4) character female dissident to her husband, and (5) female teaser characters.
\end{abstract}

Keywords:

Sundanese culture; female characters; tafsir ayat suci Leleunyapeun.

\section{A. PENDAHULUAN}

Kajian tafsir nusantara bisa dikatakan produk budaya yang lahir dari proses dialektika antara mufasir dengan realitas budaya yang ada. Dalam konteks tafsir Sunda, latar budaya cukup berpengaruh terhadap mufasir dan karyanya. Meski umumnya didominasi deskripsi wacana Qur'ani, tetapi tidak sedikit nuansa budaya Sunda pun turut mewarnai. Keterpengaruhannya terutama berkaitan erat dengan unsur bahasa. Bahasa 
Nadia Laraswati, Syahrullah dan Ahmad Gibson Al-Bustomi

bagi orang Sunda merupakan media artikulasi simbol budaya dan pandangan hidupnya.

Budaya Sunda sebagai budaya lokal masyarakat Jawa Barat terpengaruhi dengan adanya Islam, dengan nilai budaya sunda masuk kedalam ragam kehidupan sosial budaya kaum Muslim, hasil dari adaptasi Islam dan budaya setempat. Hal ini menunjukkan kuatnya pengaruh budaya lokal dalam membentuk konstruksi identitas Islamicate Sunda. ${ }^{1}$ Terlihat dengan menyebarnya penerbitan-peneribatan tentang Islam di era modern, yang berbentuk seperti tafsir Sunda beraksara Roman-Latin yang mulai dipublikasikan. Tafsir jenis ini umumnya beredar di toko buku, sebagian kecil ada pula di toko kitab. ${ }^{2}$ Publikasi tafsir Sunda menjadi faktor utama terhadap penguatan Islam di masyarakat dengan aksara RomanLatin melampaui berbagai pengajaran di mesjid-mesjid pedesaan ataupupn pesantren di Jawa Barat. $^{3}$

Tafsir atau terjemah Alquran bahasa Sunda dapat kita jadikan contoh untuk menggali keunikannya. Penelitian ini merujuk terhadap upaya orang Sunda dalam memahami Alquran ke dalam tafsir berbahasa Sunda. Bagaimana orang Sunda, mendomestikasi dan menjembatani jarak antara bahasa Alquran ${ }^{4}$

${ }^{1}$ R. Kevin Jaques, "Islamicate Society", dalam Richard C. Martin, Encyclopaedia of Islam and the Muslim World Vol. 1 (New York: Macmillan, 2004), 364-365.

2 Tentang dinamika otoritas penulis tafsir di Indonesia, lihat Howard M. Federspiel, Kajian Alquran di Indonesia: dari Mahmud Yunus hingga Quraish Shihab, terj. Tadjul Arifin (Bandung: Mizan, 1996), 106-107.

${ }^{3}$ Islah Gusmian, Khazanah Tafsir Indonesia; dari Hermeneutika hingga Ideologi, Cet. I, (Jakarta: Teraju, 2003), 64. Dalam pandangannya Islah Gusmian memberikan komentar terhadap keberadaan tafsir berbahasa daerah, selain bahasa Melayu. Baginya, keberadaan tafsir berbahasa daerah lebih menonjolkan sisi pragmatis karena sebatas menjembatani pemahaman terhadap Alquran. Selain itu, tafsir berbahasa daerah juga dianggap bersifat elitis karena hanya bisa diakses oleh mereka yang berbahasa tersebut.

${ }^{4}$ Dendy Sugono, KBBI, (Jakarta: Pusat Bahasa, 2004), 23
Karakteristik kebahasaan Tafsir Ayat Suci Lenyepaneun Karya Moh.E.Hasim (Analisis Terhadap Karakter Perempuan Dalam Alquran)

dan bahasa lokal. ${ }^{5}$ Karenanya, Penggunaan nuansa budaya Sunda menjadi indikator penting sejauh mana sebuah tafsir betul-betul nyunda atau bercitarasa Sunda. Sebuah kajian awal tentang model kreatifitas pendekatan tafsir kitab suci bernuansa etnis lokal Nusantara yang berusaha mengakomodasi kekayaan latar budayanya. ${ }^{6}$

Khazanah Islam Nusantara yang hingga saat ini masih menarik dikaji adalah keberadaan manuskrip maupun karya buah tangan ulama. Ada banyak karya ulama Nusantara, baik di bidang Sejarah, Tasawuf, Fiqih, maupun Tafsir. Tumbuhnya karyakarya menandai tumbuhnya semangat keilmuan yang dibangun di atas dialektika konstruktif. Karya-karya yang lahir adalah sebuah respon terhadap kebutuhan materi keislaman. Sebagai contoh tafsir Ayat Suci Lenyepaneun karya Moh. E Hasim adalah salah satu tafsir Sunda yang memiliki kelebihan dibandingkan dengan karya tafsir Sunda lainnya. Ada beberapa alasan mengapa tafsir Moh. E. Hasim layak untuk dikaji.

Pertama, di antara mufasir ataupun penerjemah Alquran di tanah Sunda, Hasim adalah satu-satunya orang yang bukan dari kalangan pesantren ataupun lembaga pendidikan. Kedua, Hasim berhasil merangkai tafsirnya dalam nuansa kebahasaan yang indah dan mudah dimengerti, padahal ia bukanlah berlatarbelakang pendidikan formal. Kekuatan tafsir ini terletak pada penggunaan bahasa Sunda yang indah, sehingga karya ini menjadi salah satu karya yang memiliki struktur bahasa Sunda yang paling Indah. Di samping ahli dalam bahasa Sunda, Moh. E Hasim juga menguasai bahasa Arab dengan baik.

Dari penuturan di atas, tafsir Ayat Suci Lenyepaneun karya Moh. E. Hasim layak

5 Benjamin G. Zimmer, Al-'Arabiyyah and Basa Sunda: Ideologies of Translation and Interpretation among the Muslims of West Java, (Studia Islamika, 7 (3): 2000), 31.

6 Kearifan lokal (local genius, local wisdom) mengandung arti kemampuan dan kreatifitas kebudayaan setempat dalam menghadapi pengaruh kebudayaan asing. Lihat Ajip Rosidi, Kearifan Lokal dalam Perspektif Budaya Sunda (Bandung: Kiblat, 2011), 29-30. 
Nadia Laraswati, Syahrullah dan Ahmad Gibson Al-Bustomi
Karakteristik kebahasaan Tafsir Ayat Suci Lenyepaneun Karya Moh.E.Hasim (Analisis Terhadap Karakter Perempuan Dalam Alquran) untuk ditelaah. Seorang yang tidak memiliki latar belakang pendidikan agama maupun pendidikan formal berhasil menyuguhkan sebuah karya tafsir yang dalam kebiasaannya selalu dilakukan oleh mereka yang berlatar belakang pendidikan agama.

\section{B. PEMBAHASAN}

\section{Gaya Bahasa Sunda dalam Tafsir Ayat Suci Lenyepaneun}

Islah Gusmian dalam kajiannya melihat peran yang sangat besar dari karya-karya tafsir berbahasa Indonesia dalam kajian Alquran di Indonesia. Menurutnya, karya-karya berbahasa Indonesia memiliki keluasan untuk diakses oleh masyarakat Indonesia daripada karyakarya berbahasa Arab-Melayu ataupun bahasa daerah. $^{7}$ Bahkan baginya karya-karya berbahasa daerah memiliki ruang yang sangat sempit dalam konteks keindonesiaan, karena hanya bisa diakses oleh mereka yang berbahasa tersebut. ${ }^{8}$

Pandangan ini secara tidak langsung menegasikan eksistensi karya-karya berbahasa non-Indonesia dalam transformasi Islam. Dalam skala yang luas, karya tafsir berbahasa Indonesia memerankan fungsinya yang luas sebagai media tafsir Alquran. Padahal, seperti halnya bahasa Melayu atau Indonesia dan bahasa-bahasa lainnya, bahasa daerah seperti Jawa, Sunda, Bugis dan sejenisnya memiliki kesempatan yang sama untuk membahasakan Alquran. Bahkan bisa dikatakan bahwa justru bahasa daerah dengan segala lipatan sejarah di dalamnya memiliki kemampuan lebih daripada bahasa Indonesia dalam membahasakan Alquran.

Di sisi lain, keragaman nusantara dengan bahasanya menjadikan bahasa Melayu tidak bisa diakses secara luas oleh masyarakat. Ada kelompok-kelompok masyarakat yang tidak mampu berbahasa Melayu. Maka ketika Islam mulai menyebar ke pelosok nusantara, bahasa lokal mengambil alih peran bahasa Melayu

\footnotetext{
${ }^{7}$ Islah Gusmian, Khazanah Tafsir Indonesia; dari Hermeneutika hingga Ideologi, 63.

${ }^{8}$ Islah Gusmian,Khazanah Tafsir Indonesia; dari Hermeneutika hingga Ideologi, 64.
}

dalam membangun komunikasi dengan masyarakat. Bahasa lokal digunakan dalam sebagai pengantar pendidikan di lembagalembaga pendidikan, ceramah, maupun penulisan karya. Misalnya dalam tradisi tafsir di suku Bugis, ada karya tafsir berbahasa Bugis Tafsir Al-Qur'an al-Karim Mabbasa Ogi "karya Anre Guruttā (selanjutnya: AG.) H. Abd. Muin Yusuf dkk. ${ }^{9}$ Tafsir ini ditulis guna memenuhi kebutuhan masyarakat Bugis terhadap kajian Islam yang bisa dimengerti oleh mereka.

Begitu pula ketika bahasa Indonesia diresmikan sebagai bahasa resmi, di satu sisi menyisihkan peran bahasa daerah sebagai bahasa komunikasi masing-masing daerah. Dalam konteks kajian Alquran, karya berbahasa Indonesia tidak bisa diakses oleh semua daerah. Setidaknya hal ini diakui oleh Moh. E. Hasim. Hasim selalu menyinggung proses awal dirinya mempelajari Islam melalui buku. Ia menemukan kesulitan memahami dan mengartikulasikan apa yang dibacanya. Baginya, bahasa ibu, dalam hal ini Sunda, memiliki ikatan emosional dengannya, sehingga lebih mudah baginya memahami karya dalam bahasa Sunda. ${ }^{10}$

Bahasa memegang peran penting dalam eksistensi sebuah etnis atau kelompok. Bahasa merupakan representasi, cerminan suatu kebudayaan; dan kebudayaan menentukan serta mendukung etnisitas. ${ }^{11}$ Dalam kata lain, bahasa adalah identitas etnis, jika bahasa punah, maka punahlah etnis dimaksud.

9 Muhammad Yusuf, Perkembangan Tafsir alQur'an di Sulawesi Selatan : Studi Kritis Tafsîr AlQur'ân al-Karîm Mabbasa Ogi "karya Anre Gurutta" (selanjutnya: AG.) H. Abd. Muin Yusuf dkk, Jurnal Bimas Islam, Vo. 2, No. 1, 2009, 136-177.

${ }^{10}$ Hasim menegaskan bahwa bahasa Ibu memiliki kekuatan untuk menjabarkan Alquran. Ia mencontohkan kelemahan bahasa Indonesia yang diangapnya masih sangat miskin untuk menrjemahkan beberapa kata musytarok dalam al-Quran, misalnya kata alâ yang selali diartikan “ kepada”. Di sinilah ia lebih melihat peran yang besar dalam bahasa Sunda untuk menafsirkan Alquran. Dalam tesis Jaja Zakarsy, Bahasa Sunda dalam Penafsiran Alquran, 3.

${ }^{11}$ Mikihiro Moriyama, Semangat Baru, 13. 
Nadia Laraswati, Syahrullah dan Ahmad Gibson Al-Bustomi

Vitalitas bahasa sebagai identitas etnis dijadikan pintu oleh para Ulama untuk melakukan transformasi Islam. Di sini bahasa lokal menjadi pengantar untuk kegiatan dakwah, salah satunya adalah dalam bentuk karya buku.

Dalam tradisi tulis menulis masyarakat Sunda, karya-karya berbahasa Sunda juga banyak ditulis guna membangun efektifitas komunikasi antara Islam dan masyarakat Sunda. Ada banyak karya keislaman ditulis dalam bahasa Sunda, misalnya bidang Fiqih, Tasawuf, dan Tafsir. Dari sini jelas bahwasanya penggunaan bahasa lokal setidaknya memiliki tiga makna.

Pertama, membangun efektifitas komunikasi, bahwa bahasa lokal sangat memudahkan bagi komunikasi dakwah Islam. Islam yang disampaikan dalam balutan bahasa lokal menjadi sangat mudah dimengerti dan dipahami oleh masyarakat.

Kedua, menjaga eksistensi bahasa lokal. Dengan adanya penggunaan bahasa lokal, baik dalam bahasa lisan maupun tulisan, maka secara tidak langsung menjaga eksistensi bahasa lokal. Ini artinya menjaga eksistensi etnis dimaksud.

Ketiga, memperluas fungsi sosial bahasa. Sebuah bahasa akan berkembang dengan kemampuannya menjabarkan tema-tema yang beragam. Misalnya, bahasa Inggris tidak sebatas bahasa komunikasi, melainkan juga menjadi bahasa ilmu pengetahuan dan teknologi. Artinya, bahasa Inggris memiliki fungsi yang sangat luas dari sekedar bahasa komunikasi sehari-hari.

Begitupun dengan penggunaan bahasa lokal dalam kajian Islam khususnya Tafsir. Jika sebelumnya bahasa dimaksud sebatas bahasa komunikasi atau perdagangan, kini juga menjadi bahasa tafsir. Kekayaannya bertambah luas dengan kemampuannya mengesplorasi Alquran. ${ }^{12}$

\footnotetext{
${ }^{12}$ Terkait peran social bahasa Sunda, Hawe Setiawan dengan Pusat Studi Sunda terus mengembangkan bahasa Sunda untuk dijadikan bahasa Ilmu Pengetahuan. Hal ini ditandai dengan diterbitkannya Jurnal Seri Sundalana, di mana pada tiap-tiap edisi diisi oleh tema-tema tertentu seperti ilmu
}

Karakteristik kebahasaan Tafsir Ayat Suci Lenyepaneun Karya Moh.E.Hasim (Analisis Terhadap Karakter Perempuan Dalam Alquran)
Berbagai upaya untuk menegakkan eksistensi bahasa Sunda terus dilakukan oleh masyarakat Sunda. Salah satu upaya yang dilakukan adalah memperluas fungsi sosial bahasa Sunda. Bahasa Sunda tulisan tidak hanya berupa karya sastra, seperti, cerita pendek dan puisi. Atau paling banter untuk membuat laporan jurnalistik. Tetapi bisa juga digunakan untuk menyampaikan pikiran tentang politik, ekonomi, sosial, dan budaya. Di Pusat Studi Sunda, ada jurnal enam bulanan yang bernama Sundalana. Salah satu misi yang diemban jurnal tersebut adalah memberdayakan bahasa Sunda sebagai bahasa keilmuan. Setiap terbitannya dibuat dalam tiga bahasa yaitu bahasa Sunda, Indonesia, dan Inggris. ${ }^{13}$

Hal ini terjadi pula dalam kajian karya Hasim, Ayat Suci Lenyepaneun. Penggunaan bahasa Sunda dalam karyanya ini mengandung tiga makna di atas. Misalnya, Hasim menyoroti kurangnya buku-buku keislaman dalam berbahasa Sunda. Ia mencontohkan bahwa dahulu ketika hendak mempelajari Islam ia banyak menemukan kesulitan memahami buku-bukunya. Ada buku yang bagus dalam bahasa Indonesia namun bahasanya terlalu ilmiah sehingga sulit bagi masyarakat awam membacanya. Atas dasar itulah, ia terdorong untuk menulis karyakaryanya dalam bahasa Sunda agar masyarakat mudah memahaminya.

Penggunaan bahasa Sunda sebagai media penyampaian penafsiran Alquran dan memiliki signifikansi bagi tersampaikannya penafsiran Alquran, tidak bisa dilepaskan dari proses dialog yang dibangun mufasir dengan Alquran. Merujuk kepada teori Gadamer

pengetahuan alam, sastra, dakwah, dan sejenisnya. Jurnal Seri Sundalana kini telah mencapai edisi ke-6.

${ }^{13}$ Pusat Studi Sunda (PPS) didirikan dalam rangka menjaga dan mengembangkan warisan budaya Sunda. PPS digawangi oleh tokoh-tokoh sastrawan Sunda, di antaranya Ajip Rosidi, Hawe Setiawan, dan sejunlah sastrawan Sunda lainnya. Jurnal Sundalana hanyalah salah satu media pengembangan budaya Sunda. Di sini tersedia dokumentasi buku-buku yang terkait dengan sejarah Sunda, karya-karya Sunda di berbagai bidang, literatur berbahasa Belanda dan Inggris, dan berbagai hasil penelitian. 
Nadia Laraswati, Syahrullah dan Ahmad Gibson Al-Bustomi
Karakteristik kebahasaan Tafsir Ayat Suci Lenyepaneun Karya Moh.E.Hasim (Analisis Terhadap Karakter Perempuan Dalam Alquran) tentang Fusion of Horizon, di mana di dalamnya terjadi peleburan cakrawala teks dan pembaca melalui dialog, maka hal ini terkait erat dengan keberadaan bahasa.

Proses dialog ini tersebut tidak mungkin terjadi tanpa sebuah media bahasa. Menurut Gadamer bahasa merupakan suatu realitas yang tidak bisa dipisahkan dari pengalaman, pemahaman, ataupun pikiran manusia. merupakan medium pengalaman Hermeneutik. $^{14}$ Dengan demikian maka bahasa yang umum harus dicari dalam setiap pengalaman Hermeneutik. Sebab jika para filsuf berbicara dengan menggunakan suatu bahasa yang tidak seorangpun mengerti, ini berarti sama saja mereka tidak berbicara apaapa (nihil). Dengan ini Gadamer mau menegaskan bahwa persoalan bahasa adalah tugas Hermeneutik. Pemahaman hanya mungkin dimulai bila bermacam-macam pandangan menemukan satu bahasa umum untuk saling bercakap-cakap. ${ }^{15}$

Dalam penerjemahan, Hasim menegaskan bahwa setiap bahasa memiliki kesulitan tatkala harus menerjemahkan sebuah bahasa asing. Ia mencontohkan, dalam istilah bahasa Sunda dikenal istilah kurung batokeun. Jika diterjemahkan ke dalam bahasa Indonesia, sulit ditemukan bahasa yang sepadan. Kurung kita terjemahkan sebagai "kurungan", sementara batokeun diartikan "tempurung kelapa". Jika disatukan, maka terjemahannya adalah "kurungan tempurung kelapa". 16

Begitupun dengan bahasa Alquran, ada banyak yang tidak dimiliki padanannya dalam bahasa Sunda. Hasim menegaskan bahwa kelebihan Alquran adalah bahwasanya ia bisa diterjemahkan oleh setiap zaman yang

${ }^{14}$ Fransiskus Xaverius Erwin, Hermeneutik Filosofis menurut Hans-Georg Gadamer. (Pematang siantar: t.p, 1993), 69.

15 E. Sumaryono, Hermeneutik. (Yogyakarta: t.p, 1984), 74.

${ }^{16}$ Padahal yang dikehendaki istilah tersebut adalah sifat menutup diri seseorang dari dunia luar, orang yang hanya mengenal tradisinya saja, tanpa mau membuka diri dari tradisi dan buda di luarnya. Padahal kehidupan itu bukan hanya dunianya saja, melainkan sangat luas. Dalam tesis Jaja Zakarsy, Bahasa Sunda dalam Penafsiran Alquran, 11. memiliki karakter bahasa dan budaya berbeda, namun tetap tidak mengaburkan substansinya.

Untuk menjembatani jurang antara bahasa Sunda dan bahasa Alquran, maka Hasim memilih menggunakan kearifan lokal sebagai media penerjemahan. Bahasa Sunda yang ia pilih merupakan bagian tak terpisahkan dari kehidupan masyarakat Sunda. Di sini Hasim melakukan reinterpretasi, yaitu menginterpretasi ulang makna-makna yang terkandung dalam kearifan lokal tersebut agar tetap produktif.

\section{a. Perpaduan Bahasa dan Serapan}

Sebagaimana dijelaskan sebelumnya, bahwa dua tujuan penggunaan bahasa Sunda oleh Moh. E. Hasim, yaitu menjaga eksistensi bahasa Sunda dan efektifitas transformasi kandungan Alquran ke dalam masyarakat Sunda, telah tercapai dengan baik. Ia tidak hanya mampu menghadirkan semangat baru untuk penulisan karya-karya berbahasa Sunda, akan tetapi juga telah melahirkan semangat baru untuk mengkaji Alquran melalui bahasa Sunda. Jika diteliti secara seksama, ada dua bagian bahasa yang sama-sama memberikan kontribusi dalam upaya tersampaikannya penafsiran kepada audien.

Pertama, Moh. E. Hasim menggunakan bahasa Sunda yang digunakan sehari-hari. Bahasa sehari-hari menjadi pilihan Hasim karena dengan bahasa yang sehari-hari akan lebih mudah dipahami oleh pembaca. Bahasa sehari-hari yang dimaksud dalah bahasa Sunda yang biasa diucapkan dalam dialog dan komunikasi di masyarakat.

Kedua, sebagai bagian dari upaya menegaskan eksistensi bahasa Sunda lainnya, Hasim juga memasukkan kosa kata ilmiah, baik yang berasal dari bahasa Indonesia maupun bahsa asing. Tujuannya adalah agar bahasa Sunda semakin luas fungsi sosialnya, tidak hanya sebatas pada karya-karya sastra, akan tetapi juga mengakomodir bahasa asing, tanpa melemahkan fungsi bahasa Sunda.

Moh. E. Hasim juga banyak melibatkan bahasa asing dalam rangka memperjelas uraiannya. Dalam hal ini Hidayat Suryalaga memberikan komentarnya, bahwa Moh. E. 
Nadia Laraswati, Syahrullah dan Ahmad Gibson Al-Bustomi

Hasim berhasil menggabungkan bahasa Sunda kuno dan bahasa asing sebagai media mengungkap kandungan Alquran. Hasim berhasil memadukan antara bahasa Sunda asli, serapan, dan sekaligus istilah dan kosa kata asing. Hal ini baginya dianggap sebagai kecerdikan Hasim karena berhasil meracik gabungan bahasa-bahasa sehingga menjadi sebuah rangakain kalimat yang indah dan enak dibaca. ${ }^{17}$

Peran kosa kata atau istilah asing ia pergunakan untuk lebih menjelaskan uraiannya tersebut. Moh. E. Hasim memiliki kontak yang luas dengan bahasa-bahasa asing, di antaranya Inggris, Belanda, dan Jepang. Bahkan untuk kedua bahasa pertama ia pernah menjadi dosen bagi masing-masing dari keduanya. Tak heran jika kemudian banyak kosa kata Inggris dan Belanda yang ia pakai. Hal ini dapat dilihat pada penasirannya dalam QS. al-Baqarah [2]: 10 "Dina ngudag-ngudag harta jeung tahta, kaom munafikin ngetrukkeun sagala taktik jeung atrekah, teu paduli ngarah nagrinah jeung linyok bohong asal maksudna tinekanan, rerebut jeung hahawek meakeun batur teu aya nu dipahing da nu dijieun patokan ku maranehna mah papagon Machievelli nu unggelna; "intention justifies all means" atawa " Het doel heiligi de middelen" hartina : Tujuan ngahalalkeun sagala cara." 18 Disini terlihat jelas bagaimana Hasim menguraikan penafsiran orang yang mempunyai penyakit hati dengan menggunakan bahasa serapan lain selain bahasa Sunda yang sudah melekat pada tafsirnya. Begitupun dengan tafsirannya pada QS. Al-Lahab [111]: 1, ${ }^{19}$ Hasim dalam tafsirnya menjelaskan ayat ini dengan memadukan antara bahasa Sunda asli, serapan, dan sekaligus istilah dan kosa kata asing. Hal ini baginya dianggap sebagai kecerdikan Hasim karena berhasil meracik gabungan bahasa-bahasa sehingga menjadi sebuah

\footnotetext{
${ }^{17}$ Pengantar Hidayat Suryalaga, dalam Ayat Suci Lenyepaneun, xii-xiii. 36.

${ }^{18}$ Moh. E. Hasim, Ayat Suci Lenyepaneun, Jilid 1,

${ }^{19}$ Moh. E. Hasim, Ayat Suci Lenyepaneun, Jilid.
}

Karakteristik kebahasaan Tafsir Ayat Suci Lenyepaneun Karya Moh.E.Hasim (Analisis Terhadap Karakter Perempuan Dalam Alquran)

rangakain kalimat yang indah dan enak dibaca. Moh. E Hasim menolak prinsip stratifikasi sosial berdasarkan status sosial.

Untuk itu, ia lebih memilih bahasa menengah, atau dikenal dengan bahasa loma. Bahasa loma merupakan pertengahan antara bahasa kasar dan bahasa sangat halus. Bahasa ini dipakai dalam komunikasi masyarakat menengah, namun undak usuk basa tetap dipakainya. Dalam hal ini penggunaannya hanya berkisar pada hal-hal yang bersifat uluhiyah. Artinya, bahasa lemes yang dahulu dipakai untuk berkomunikasi dengan pejabat atau saudagar, oleh Moh. E. Hasim dipakai dalam komunikasi dengan Tuhan. Di samping itu, bahasa halus yang dahulu dipakai untuk komunikasi dengan para bangsawan, ia pergunakan dalam dialog yang menunjukkan nuansa rasa hormat, bukan lagi stratifikasi sosial.

\section{b. Penggunaan Uslub Sunda dalam Terjemah}

Ada dua kecenderungan yang berkembang dalam teknik penerjemahan Alquran. Pertama, mengikuti secara ketat struktur bahasa Arab. Terjemahan suatu ayat mengikuti struktur bahasa Arab, mengikuti terjemah urutan kalimat dalam bahasa Arab. Tipe pertama ini banyak ditemukan dalam karya tafsir yang menggunakan huruf pegon dengan metode menggantung. Artinya terjemahan berada di bawah kalimat. Hal ini nampak seperti dalam karya K.H. Bisri Mustofa dengan al-Ibriz-nya dan Raudhat alIrfän karya K.H. Ahmad Sanusi. Kedua, penerjemahan mengikuti struktur bahasa ibu. Terjemahan tidak lagi harus mengikuti pola struktur bahasa Arab, melainkan cukup dengan menerjemahkan tiap-tiap kata, kemudian terjemahan tersebut dirangkai dengan menggunakan pola struktur bahasa ibu. Pola penerjemahan seperti ini terdapat dalam karya-karya yang menggunakan huruf latin, bukan huruf pegon. Di sini terjadi pergeseran pola penyusunan, di mana huruf latin menjadi medianya.

Hasim adalah penerjemahan yang mengikuti uslub Sunda karena hal itu akan mempermudah sebuah kalimat dipahami. E. 
Nadia Laraswati, Syahrullah dan Ahmad Gibson Al-Bustomi
Karakteristik kebahasaan Tafsir Ayat Suci Lenyepaneun Karya Moh.E.Hasim (Analisis Terhadap Karakter Perempuan Dalam Alquran)
Hasim tidak mengikuti struktur bahasa Arab secara ketat, akan tetapi mengikuti struktur bahasa Sunda dengan tidak mengurangi substansi ayat. Misalnya terdapat pada penafsiran beliau dalam QS. al-Fatihah [1]: 2 Hasim menulis:“ ari sagala puji kanggo/kagungan Allah pangeran nu murbeng alam. "20 Model serupa juga dilakukan dalam Tarjamah al-Qur'an Basa Sunda karya Kanwil Depag Jawa Barat dan al-Amin: alQur'an tarjamah Sunda karya K.H. Qomaruddin dkk. Di sini kita bisa melihat perbedaan Raudhat al-Irfän dan Ayat Suci Lenyepaneun terletak pada pola penerjemahan, di mana K.H. Ahmad Sanusi sangat ketat mengikuti struktur bahasa Arab. Adapun E. Hasim lebih fleksibel dengan tidak mengikuti pola bahasa Arab. Sebagai contoh, dalam menerjemahkan ayat, K.H. Ahmad Sanusi meletakkan makna kalimat menggantung di bawahnya, sama dengan pola kitab-kitab berbahasa Jawa atau al-Ibriz karya Bisyri Mustofa. Dalam surat al-fätihah dia menulis : alhamdu (ari sakabeh puji) Lillahi (eta kagungan Allah).

\section{c. Babasan dan Pribasa}

Babasan dan paribasa adalah salah satu cagar budaya Sunda yang memiliki makna dalam budaya Sunda. Babasan dalam bahasa Indonesia dikenal sebagai ungkapan, sedangkan paribasa dikenal dengan peribahasa. Ungkapan adalah kelompok kata yang khusus menyatakan suatu maksud dengan arti kiasan.

Babasan adalah segala sesuatu yang diungkapkan, dibangun dari gabungan kata yang maknanya tidak sama dengan penyatuan makna setiap kata yang membentuknya, tetapi maksudnya sudah dipahami secara umum, ${ }^{21}$ atau ucapan baku yang dipakai dalam arti pinjaman. $^{22}$ Arti babasan sama dengan bilangan, yaitu ucapan-ucapan yang artinya tidak seperti adanya, susunan bahasanya ringkas, sedikit kata pembentuknya.

\footnotetext{
${ }^{20}$ Moh. E. Hasim. Ayat suci..juz I , 1.

${ }^{21}$ R. Stjadibrata, Kamus Basa Sunda, (Bandung: Kiblat Buku Utama, 2005), 61.

${ }^{22}$ Lembaga bahasa jeung sastra Sunda, Kamus Umum Basa Sunda, Bandung: Tarate, 1995, 43.
}

${ }^{23}$ Misalnya nyalindung $k a$ gelung, artinya mengandalkan usaha orang tua, ngadu angklung, berdebat dalam hal yang tidak berguna. ${ }^{24}$

Adapun peribahasa adalah kelompok kata/kalimat yang tetap susunannya, mengiaskan maksud tertentu. ${ }^{25}$ Dengan kata lain, paribasa adalah perbandingan yang menjadi lambang perilaku membentuk suatu ucapan, yang jelas susunan dan pengucapannya. ${ }^{26}$ Paribasa dapat diartikan sebagai ungkapan atau kalimat ringkas, padat, yang berisi perbandingan, perumpamaan, nasihat, prinsip hidup atau aturan tingkah laku. ${ }^{27}$ Paribasa atau peribahasa biasa digunakan dalam tata bahasa Sunda untuk lebih menjelaskan maksud yang hendak disampaikan dari yang bercerita kepada yang diceritakan.

Misalnya ungkapan babalik pikir yang artinya insaf. Jika diterjemahkan berdasarkan tiap-tiap kata, babalik artinya kembali, pikir artinya berfikir. Jika digabungkan menjadi “ kembali berfikir". Ada lagi babasan "eleh deet" artinya " mengalah supaya cepat beres". Dari makna kata perkata, eleh artinya mengalah, deet artinya dangkal. Jika disatukan akan menjadi "mengalah dangkal".

Ungkapan dan peribahasa merupakan unsur bahasa yang dapat menggambarkan budaya suatu masyarakat bahasa pada zamannya atau unsur budaya yang memiliki nilai sebagian besar menjadi pedoman atau larangan dalam aktivitas manusia berbudaya. Babasan dan paribasa digunakan untuk menyatakan suatu maksud (informasi dari hasil aktivitas manusia dengan nilai yang baik atau buruk. Nilai budaya yang baik cenderung dipedomani, sedangkan yang buruk tidak

\footnotetext{
${ }^{23}$ Rahmat Taufiq Hidayat, dkk, Peperenian Urang Sunda. (Bandung: Kiblat, 2005), 195.

${ }^{24}$ Rahmat Taufiq Hidayat dkk, Peperenian Urang Sunda, 195.

${ }^{25}$ T Fatimah Djajasudarma, Nilai Budaya Dalam Ungkapan dan Peribahasa Sunda, Cet. I,(Jakarta: Depdikbud, 1997), 14.

${ }^{26}$ Rahmat Taufiq Hidayat dkk,Peperenian Urang Sunda, 39.

${ }^{27} \mathrm{~T}$ Fatimah Djajasudarma,Nilai Budaya Dalam Ungkapan dan Peribahasa Sunda, 14.
} 
Nadia Laraswati, Syahrullah dan Ahmad Gibson Al-Bustomi

untuk dipedomani. ${ }^{28}$ Terkait dengan hal tesebut, babasan dan paribasa mempunyai dua tujuan: dari segi makna mengungkapkan masalah perbandingan, perumpamaan, nasihat, prinsip hidup dan tingkah laku serta aturannya-aturannya, menyangkut pula laranglarangannya; dan dari segi budaya menyangkut tingkah laku dalam komunikasi antara manusia dengan manusia, manusia dengan kehidupan, menusia dengan kerjanya, manusia dengan waktu, dan manusia dengan alam. ${ }^{29}$

Moh. E Hasim memberikan menyampaikan penafsirannya melalui perangkat-perangkat kebahasaan Sunda, salah satunya melalui penggunaan babasan dan paribasa. Keduanya dipakai untuk menyampaikan makna Alquran. Ini menandakan bahwa Moh. E Hasim sangat jeli menggunakan media. Sebagaiaman dketahui, bahwa babasan dan peribahasa merupakan bahasa ringkas yang mengandung makna luas. Ayat-ayat Alquran ia sampaikan maknanya melalui perangkat babasan dan peribahasa. ${ }^{30}$

Konsep ihsān dalam QS. al-Baqarah[2]: 83dipaparkan oleh Moh. E Hasim dengan sebuah babasan yang sangat simpel namun mengandung makna yang sangat luas dan dalam. ${ }^{31}$ Babasan yang ada dalam pemaparan ini adalah hade gogog hade tagog yang berarti bagus dalam perkataan, penampilan dan perilaku. ${ }^{32}$ Berbuat baik seperti diperintahkan Allah dalam ayat ini diartikan oleh Moh. E.

\footnotetext{
${ }^{28} \mathrm{~T}$ Fatimah Djajasudarma, Nilai Budaya Dalam Ungkapan dan Peribahasa Sunda, 3.

${ }^{29} \mathrm{~T}$ Fatimah Djajasudarma, Nilai Budaya Dalam Ungkapan dan Peribahasa Sunda, 4.

${ }^{30}$ Hasim mengisahkan bahwa dirinya akan merasakan kesenangan untuk membaca suatu buku atau tulisan yang menggunakan bahasa yang sangat indah dengan nuansa sastra. Hasim menyukai membaca buku berbahasa Inggris atau Belanda yang bernuansa sastra. Terkait hal ini Hasim

${ }^{31}$ Hasim menulis:" "Ari nu dimaksud ihsan teh nya eta: 1. hade gogog hade tagog, tingkah laku jeung budi basa kudu mata nyenangkeun hate; 2. mere mawe satungtung kadad kaduga; jeung 3. ihlas ngabantu ku tanaga jeung pikiran.'Moh. E Hasim, Ayat Suci leunyeupaneun..., Juz 1, 188.

${ }^{32}$ Rahmat Taufiq Hidayat, dkk, Peperenian Urang Sunda, 214.
}

Karakteristik kebahasaan Tafsir Ayat Suci Lenyepaneun Karya Moh.E.Hasim (Analisis Terhadap Karakter Perempuan Dalam Alquran)
Hasim dengan sikap, perbuatan dan penampilan yanga bagus di hadapan orang tua. Kesemuanya ini terangkum dalam peribahasa hade gogog hade tagog. Orang Sunda paham maksud babasan ini.

\section{d. Penggunaan Bahasa Metafor}

Dalam berkomunikasi dengan audiensi, Alquran salah satunya juga menggunakan bahasa metaforis terutama jika terkait hal-hal yang bersifat eskatologis. Pada dasarnya bahasa metaforis berfungsi membangun pengalaman rasa pada suatu obyek yang tak pernah ia rasakan dan berada jauh di balik teks dengan mempertemukan antara ikatan emosional dan pemahaman kognitif.

Misalnya Hasim menafsirkan QS. alQari'ah [101]: 1-5 Secara jeli Moh. E. Hasim memberikan gambaran seputar kejadian kiamat dengan bahasa yang memang sudah dipahami oleh masyarakat Sunda. Di sini kita melihat bahwa beberapa kata seperti " pating beledugna gunung, batu sagede-gede leuit ${ }^{33}$ pating galutuk, tatangkalan pating dorokdok ${ }^{\prime \prime 34}$ menggambarkan geografis priangan yang memang merupakan daerah pegunungan. Kedahsyatan kiamat digambarkan dengan gunung yang meletus, di mana gunung meletus memang pernah dirasakan masyarakat Sunda seperti gunung Galunggung pada tahun 1982. Begitu pula

${ }^{33}$ Leuit (lumbung Jw.): adegan tempat ngampihan pare. R. Satjadibrata, Kamus Basa Sunda....., 227.

34 Hasim menulis:" " Dina poe eta sakumna manusa bakal nyaksian kaadian alam nu luar biasa hebatna kalayan dadak sakala, mimitina aya sora ngageleger tarik taya papadana, lain ngan saukur matak tagiwur salelembur tapi matak geumpeur jeung gugup sakolong langit. Tah dina poe ieu datangna tunggara nu tunggara rongkah taya wiwilanganana. Bumi genjlong dibarung ku pating beledugna gunung, tatangkalan pating dorokdok, batu sagede-gede leuit pating galutuk kabawa urug. Jelema paburisat rawahriwih pating jarerit bari patarik-tarik lumpat ngaler ngidul teu puguh nu dituju. Indung teu olih ka orok. Bapa poho ka anak pamajikan. Nu labuh, nu tikusruk, nu tigebrus, nu katinggang batu jeung kakayon, nu pateungggar jeung babaturanana, pabalatak di manamana lir ibarat bugang rambetuk. Kabeh gunung pating beledug muncrat saperti lebu diawurkeun ka awang-awang nepi ka angkeub teu katenjo titincakan. Tah ieu teh kaayaan dina ngamimitian kiamat kubra tea."'” Moh. E. Hasim. Ayat Suci..., Juz 30, 276. 
Nadia Laraswati, Syahrullah dan Ahmad Gibson Al-Bustomi
Karakteristik kebahasaan Tafsir Ayat Suci Lenyepaneun Karya Moh.E.Hasim (Analisis Terhadap Karakter Perempuan Dalam Alquran) dengan penggambaran batu-batu yang berjatuhan, menunjukkan bahwa masyarakat Sunda sangat paham bagaimana mengerikannya saat batu-batu di perbukitan jika terjadi longsor. Begitu pula dengan pohon-pohon yang memang ada di sekitar mereka. Gambaran kedahsyatan alam seperti gunung meletus, batu yang berjatuhan dari perbukitan, dan pohon-pohon yang bertumbangan, dijadikan alat untuk menggambarkan kejadian dahsyatnya kiamat.

\section{Karakteristik Perempuan dalam Alquran menurut Tafsir Ayat Suci Lenyepaneun}

Penelitian mengenai karakter wanita ini saya akan menganalisis menurut pandangan Moh. E. Hasim dalam tafsir Ayat Suci Lenyepaneun. Akan tetapi, lebih difokuskan pada lima karakter.

Lima karakter perempuan tersebut yaitu: (1) karakter perempuan dengan kepribadian kuat, (2) karakter perempuan yang menjaga kesuciannya, (3) karakter perempuan penghasut, (4) karater perempuan pembangkang kepada suaminya, dan (5) karakter perempuan penggoda. Adapun untuk pemaparan yang lebih rincinya sebagai berikut:

\section{a. Karakter Perempuan \\ Kepribadian Kuat}

Siapa pun tidak bisa menghindar dari tantangan yang ada, termasuk perempuan. Hal ini dicontohkan oleh Aisah yang merupakan istri dari Fir'aun. Aisah adalah tokoh yang dijadikan perumpamaan sebagai perempuan dengan karakter kuat, kuat disini diartikan dengan kuat mencapai keimanan dan ketakwaan yang tinggi. Beliau berani dalam menampakan keimanannya kepada Fir'aun. Dia tidak takut dengan acaman yang akan diberikan Fir'aun.

Adapun ayat Alquran yang bersangkutan dengan kisah tersebut adalah QS. al-Tahrim [66]: 11 :

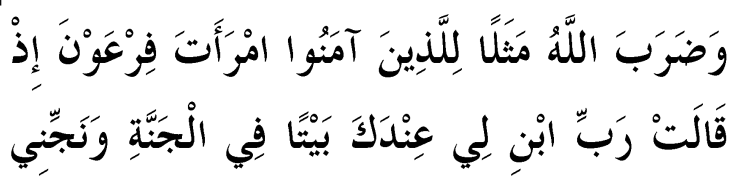

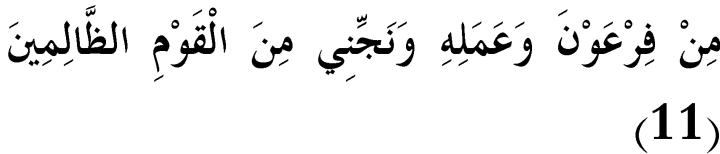

" Allah membuat isteri Fir'aun sebagai perumpamaan terhadap orang-orang beriman, ketika ia berkata: "Ya Rabbku, bangunkanlah untukku sebuah rumah di sisi-Mu di surga firdaus, dan selamatkanlah aku dari Fir'aun dan perbuatannya, serta selamatkanlah aku dari kaum yang lalim".

Dalam Tafsir Ayat Suci Lenyepaneun, Hasim menjelaskan bahwa istri Fir'aun itu bernama Aisah, begitu juga dengan karakternya, ia menulis bahwa Aisah adalah seorang perempuan yang tidak mudah terpengaruh oleh kenikmatan dunia, seperti yang tertulis dalam tafsirnya "Jiwana heunteu kapangaruhan ku murum-mubyarna dunya,, 35 Aisah tetap teguh dengan keimanan dan ketakwaan yang dipegangnya, dia tidak terpengaruhi oleh orang-orang yang kufur dan dzalim. Walaupun Aisah tinggal ditempat Kerajaan yang indah dan megah, dengan perhiasan yang berkilauan, pakaian yang bagus, dan apapun yang diinginkan oleh para wanita di dunia sudah tersedia di hadapan Aisah. Akan tetapi, Aisah tidak tergiur dengan kemanjaan dunia yang ada, dia lebih memilih tempat yang kekal yang disediakan oleh Allah.

Ciri-ciri karakter perempuan kuat berdasarkan pada kajian khazanah tafsir Ayat Suci Lenyepaneun karya Moh. E. Hasim ini, dalam Q.S. Al-Tahrim [66]: 11; bahwa perempuan yang berkarakter kuat adalah perempuan yang mampu menguatkan keimanan dan ketaqwaannya, tidak terpengaruh oleh jabatan, lingkungan maupun kenikmatan dunia. Dan sifat-sifatnya meliputi : penyayang, cerdas, sabar dan teguh pendiriannya. Pelajaran yang bisa diambil dari kisah Aisah adalah dalam kondisi apapun tidak menghalangi wanita salihah untuk beriman, keberlimpahan harta tidak membuat iman terbeli, bahkan lebih memprioritaskan akhirat daripada dunia, optimis dan

${ }^{35}$ Moh. E. Hasim, Ayat Suci Lenyepaneun, Juz. 28, 
Nadia Laraswati, Syahrullah dan Ahmad Gibson Al-Bustomi

mendukung setiap kebaikan. Hasim menuliskan dalam kitab tafsirnya terdapat pribasa "Kaliung kasiput", 36 yang artinya adalah dikelilingi oleh saudara yang kaya. Disini Hasim menjelaskan betapa beruntungnya Aisah yang dikelilingi dengan kemewahan yang ada disekitarnya. Akan tetapi kemewahan itu tidak membuatnya iman kepada Allah goyah. Karena dia lebih memilih keindahan akhirat yang kekal abadi. Terlihat jelas kecerdikan Hasim dalam menguraikan penafsirannya menggunakan pribasa, sehingga pembaca tafsirnya khusunya urang Sunda akan mengerti dengan paham maksud dari substansi ayat ini.

\section{b. Karakter Perempuan yang Menjaga \\ Kesuciannya}

Sebagai perempuan diwajibkan untuk menjaga kesuciannya dari perbuatan keji. Karena kesucian merupakan suatu kehormatan bagi yang menjaganya. Setiap lekukan indah padah tubuhnya, geraian rambut panjang adalah mahkotanya dan suara lembut yang merdu, semua itu harus dijaga kesuciannya.

Tokoh perempuan yang mewakili karater ini adalah Maryam, Maryam sejak kecil dikenal sebagai orang yang tekun dan rajin beribadah. Ia diasuh dan dibesarkan oleh Nabi Zakaria, di lingkungan tempat beribadah. Maryam berasal dari keturunan yang sangat baik dan shalih, dan ia dari kecil sudah menjadi yatim.

Adapun ayat Alquran yang berkaitan dengan kisah Maryam adalah sebagai berikut:

QS. Maryam [19]: 17

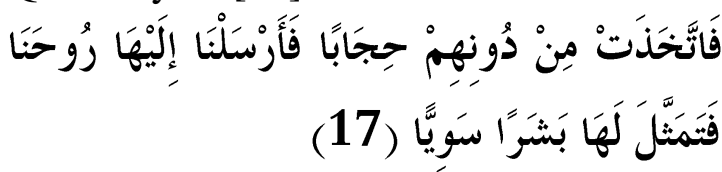

Maka ia mengadakan tabir (yang melindunginya) dari mereka; lalu di utus roh kudus kepadanya, maka ia menjelma di hadapannya (dalam bentuk) manusia yang sempurna.

Siti Maryam tinggal di mihrab yang dijaga oleh pamannya yakni Nabi Zakaria. Dalam artian beliau selalu menjaga jarak dengan laki28,245 .
Karakteristik kebahasaan Tafsir Ayat Suci Lenyepaneun Karya Moh.E.Hasim (Analisis Terhadap Karakter Perempuan Dalam Alquran)

laki, maka mustahil baginya untuk bergaul atau berzina dengan laki-laki. Di dalam tafsir Ayat Suci Lenyepaneun, bahwa Hasim menjelaskan "Yen Siti Maryam teh wanita suci, jelema nu bener-bener mangeran $k a$ mantenna. "37 Maksudnya adalah Siti Maryam adalah wanita suci, yang benar-benar iman kepada Allah. Kemudian Allah mengutus malaikat Jibril kepada Siti Maryam yang menyerupai manusia.

QS. Maryam [19]: 18

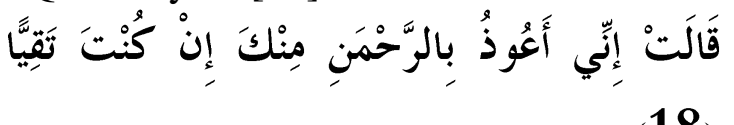

Maryam berkata: " Aku berlindung dari padamu, kepada Tuhan Yang Maha pemurah, jika kamu seorang yang bertakwa".

Hasim dalam tafsirnya menjelaskan bahwa "Boloampar 38 awewe nu can kungsi patoel cinggir jeung lalaki". Penafsiran ini menjelaskan bahwa Siti Maryam belum pernah bersentuhan dengan lalaki, apalagi jika bergaul dengan laki-laki hal itu sangat kecil kemungkinan. kecuali dengan pamannya yakni Nabi Zakaria karena dia adalah yang membesarkannya.

QS. Maryam [19]: 19

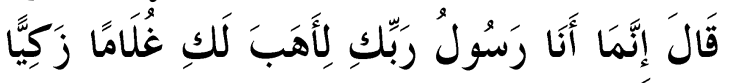

Jibril berkata: "Aku ini hanyalah seorang utusan Tuhanmu, untuk memberimu seorang anak laki-laki yang suci".

Dalam tafsiran ayat sebelumnya Hasim menjelaskan bahwa, tiba-tiba muncul di hadapan Siti Maryam seorang laki-laki. Wujud yang menyerupai seorang laki-laki tersebut adalah malaikat Jibril. Kemudian pada ayat ini Hsim menjelaskan bahwa malaikat Jibril diutus kepada Siti Maryam untuk memberi tahu bahwa dia akan mempunyai seorang anak laki-laki yang suci. 16,60 .

${ }^{37}$ Moh. E. Hasim, Ayat Suci Lenyepaneun. Jilid.

${ }^{38}$ Boloampar = boro-boro, lihat R. Satjadibrata, Kamus Basa Sunda, 76. 
Nadia Laraswati, Syahrullah dan Ahmad Gibson Al-Bustomi

Dalam hati kecil Siti Maryam berkata bahwa yang tadi datang kepadanya adalah utusan Allah, dan utusan Allah tersebut adalah malaikat, sedangkan malaikat mustahil ada yang bohong. Walaupun dia sempat kaget karena tiba-tiba di dalam kamarnya persis di hadapannya ada malaikat.

Mengenai ciri-ciri fisiknya, Alquran tidak menjelaskannya, mungkin ini karena yang ingin ditekankan pada kisah Maryam adalah mengambil pelajaran yang baik dari kisahkisahnya bukan sekedar menikmati kehebatan dan keluarbiasaannya. Adapun sifat-sifatnya ialah : tekun, rajin, sabar, tabah, ta'at. Pelajaran yang dapat diambil dari kisah Siti Maryam ini yaitu, seorang perempuan harus bisa menjaga kehormaan dan kesucian dirinya, tabah dan sabar dalam menjalankan perintah Allah, rajin dan ta'at beribadah, memiliki hubungan yang sangat erat dengan Allah, menjaga diri dari yang bukan mahramnya, keunggulan wanita di sisi Allah bukan keunggulan yang berbentuk fisik tapi keunggulan dalam ibadah dan ketaqwaan kepada Allah.

\section{c. Karakter Perempuan Penghasut}

Secara umum karakter ini termasuk kepada karakter perempuan yang berprilaku jahat. Hindun adalah tokoh utama yang dijadikan contoh pada karakter ini didalam Alquran. Firman Allah SWT QS. al-Lahab [111] : 4-5

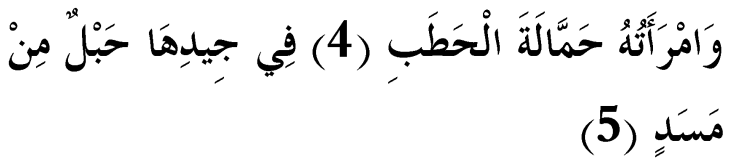

(4) Begitu pula istrinya, pembawa kayu bakar (5) Yang di lehernya ada tali dari sabut.

Dalam tafsir Ayat Suci Lenyepaneun Hasim menjelaskan bahwa istrinya pembawa kayu bakar maksudnya karena kayu bakar bisa menimbulkan api. Sedangkan api jika diartikan secara majazi adalah nafsu atau amarah. Hasim pun menjelaskan dalam pribahasa :"Seuneu hurung cai caah ulah disorang." ${ }^{39}$ Maksudnya adalah orang yang

\footnotetext{
${ }^{39}$ Moh. E. Hasim, Ayat Suci Lenyepaneun, Jilid. 30,311 .
}

Karakteristik kebahasaan Tafsir Ayat Suci Lenyepaneun Karya Moh.E.Hasim (Analisis Terhadap Karakter Perempuan Dalam Alquran)

lagi amarah atau nafsu jangan didekati. Hasim pun menjelaskan "Pamajikan Abu Lahab teh tukang ngadu-ngadu rajawisuna."40 Maksudnya adalah bahwa istri Abu Lahab adalah orang yang suka memancing amarah orang lain dan suka mengadu domba. Lebih jelasnya dia adalah seorang provokator untuk memancing amarah orang lain.

Ciri-ciri wanita yang berkarakter seperti yang sudah dijelaskan dalam Alquran dan tafsir di atas, maka perempuan yang suka mengadu domba dan suka menggosip dalam artian tukang penebar fitnah termasuk pada kategori ini. Karena Hindun atau istrinya Abu Lahab adalah orang yang berprilaku demikian.

Penafsiran ayat di atas dalam tafsir Ayat Suci Lenyepaneun ini Hasim menggunakan pribasa "Ngaliarkeun taleus ateul", 41 maksudnya adalah membicarakan kejelekan orang lain. Dengan penggunaan pribasa makna tafsir ini menjadi lebih unik dan lebih ngena pada maknanya untuk kebanyakan urang Sunda. sehingga bisa terbayangkan ilustrasi istrinya Abu Lahab yang jahat dan suka membicarakan kejelekan orang lain.

\section{d. Karakter Perempuan sebagai Istri Pembangkang kepada Suaminya}

Alquran mengisahkan istri yang tidak beriman kepada Allah dan menentang ajaran suaminya kemudian banyak membantu orang kafir. yakni istri dari Nabi Nuh dan Nabi Luth. istri Nabi Nuh sangat membangkang kepada suaminya sendiri bahkan menganggap suaminya sendiri sudah gila, hingga akhirnya ia tenggelam bersama orang-orang kafir. Sedangkan istri Nabi Luth membocorkan amanah dari suaminya agar tidak memberitahukan kedatangan dua laki-laki yang bertemu ke rumah mereka kepada kaum sodom untuk diserahkan kepada mereka.

Adapun ayat yang bersangkutan dengan kisah tersebut, diantaranya:

Q.S. Al-Tahrim [66]: 10

\footnotetext{
${ }^{40}$ Moh. E. Hasim, Ayat Suci Lenyepaneun, Jilid. 30, 311 .

${ }^{41}$ Moh. E. Hasim, Ayat Suci Lenyepaneun, Jilid. 30,311 .
} 


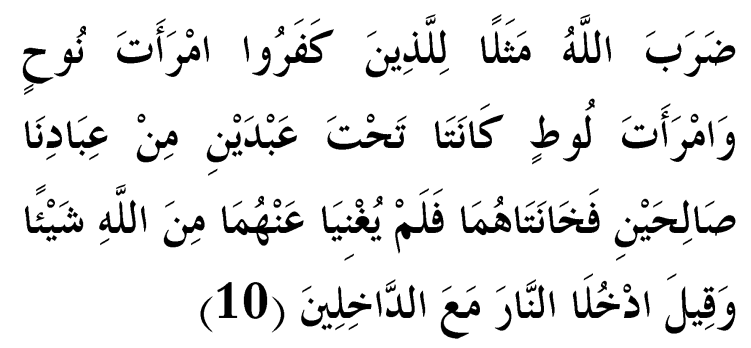

Allah membuat isteri Nuh dan isteri Luth sebagai perumpamaan bagi orang-orang kafir. Keduanya berada di bawah pengawasan dua orang hamba yang saleh di antara hamba-hamba Kami; lalu kedua isteri itu berkhianat kepada suaminya (masing-masing), maka suaminya itu tiada dapat membantu mereka sedikitpun dari (siksa) Allah; dan dikatakan (kepada keduanya): "Masuklah ke dalam jahannam bersama orang-orang yang masuk (jahannam)".

Hasim dalam kitabnya tidak menjelakan secara rinci kisah untuk kedua istri Nabi tersebut tapi dalam kitabnya Hasim menjelaskan bageitu ruginya bagi kedua istri tersebut yang tidak beriman kepada suaminya. Mereka (istri Nabi Nuh dan Nabi Luth) lebih memilih bersama orang kafir dibandingkan harus iman kepada Allah dan ajaran suaminya. Seperti yang tertulis dalam tafsirnya "Geureuha Nabi Noh jeung Nabi Lut duanana dipingpin kana jalan nu lempeng, tapi kalah ka biluk ka musuh. Ku sabab eta maranehna jadi caduk naraka babarengan jeung ahli naraka nu sejenna." "42 Maksudnya adalah istri Nabi Nuh dan Nabi Luth sudah dipimpin oleh suaminya ke jalan yang benar tapi memilih jalan yang sesat bersama orang kafir di neraka.

Hasim menggunakan undak usuk basa Sunda. Dalam hal ini penggunaannya pada sebutan atau panggilan untuk istri kedua Nabi, yakni istri Nabi nuh dan Nabi Lut yang membangkang. Hasim menggunakan geureuha yang artinya istri. Bagi tatakrama urang Sunda geureuha adalah basa lemes untuk orang lain. Hasim memakai ini karena mungkin menganggap mereka masih istri Nabi jadi kurang pantas untuk menggunakan bahasa $28,243$.

${ }^{42}$ Moh. E. Hasim, Ayat Suci Lenyepaneun, Jilid. kasar seperti "pamajikan", jadi Hasim masih menunjukkan nuansa rasa hormat kepada kedua istri Nabi tersebut.

\section{e. Karakter Perempuan Penggoda}

Kecantikan perempuan, baik itu kecantikan batin maupun kecantikan lahir dalam arti fisik harus dijaga kesuciannya. Hal ini sempat disinggung pada pembahasan karakter perempuan yang menjaga kesuciannya. Akan tetapi jauh terbalik dengan kategori karakter perempuan penggoda yang sekarang akan dibahas. Perempuan dengan karakter ini justru mencoba yang mengumbar kecantikannya dihadapan laki-laki untuk memikat hasrat laki-laki. Sehingga perempuan tidak malu untuk bertingkah laku seperti binatang yang hilang akalnya dan mengumbar auratnya dihadapan laki-laki yang bukan muhrimnya.

Zulaeha adalah salah seorang tokoh yang dijadikan contoh dalam Alquran dengan karakter penggoda. Walaupun pada akhirnya Siti Zulaeha ini bertobat di jalan Allah. Akan tetapi kisah sebelum dia bertobat dijelaskan bagaimana dia menggoda Nabi Yusuf. Hal ini dijelaskan dalam firman Allah, Alquran QS.Yusuf [12]: 23

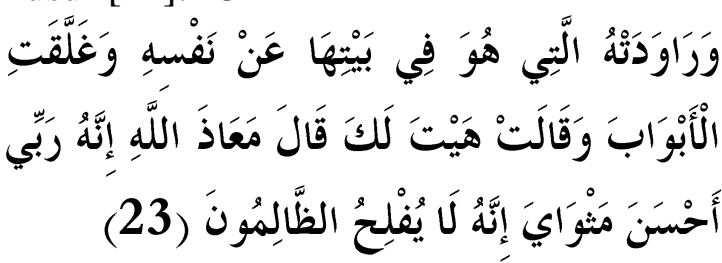

Zulaikha yang Yusuf tinggal di rumahnya menggoda Yusuf untuk menundukkan dirinya (kepadanya) dan dia menutup pintu-pintu, seraya berkata: "Marilah ke sini". Yusuf berkata: "Aku berlindung kepada Allah, sungguh tuanku telah memperlakukan aku dengan baik". Sesungguhnya orang-orang yang zalim tidak akan beruntung.

Moh. E. Hasim menggambarkan sosok Zulaikha dalam surah Yusuf dengan menggunakan banyak babasan. ${ }^{43}$ Ada banyak

${ }^{43}$ Hasim menulis:" "Istri gegeden nu ngukut Yusuf teh jenenganana Zulaikha, ngora keneh teu puputra, geulis kacida sigana mah di Mesir kaasup kana bentangna, jangkung lenjang kulitna hejo carulang, kaeureut beungeut ngadaun seureuh, tarangna lancah 
Nadia Laraswati, Syahrullah dan Ahmad Gibson Al-Bustomi
Karakteristik kebahasaan Tafsir Ayat Suci Lenyepaneun Karya Moh.E.Hasim (Analisis Terhadap Karakter Perempuan Dalam Alquran) babasan yang dipakai untuk menggambarkan kecantikan Zulaikha, seperti jangkung lenjang kulitna hejo carulang, kaeureut beungeut ngadaun seureuh, tarangna lancah mentrangan, halisna ngajeler paeh, irungna kuwung-kuwungan. Dengan menggunakan babasan, ada nilai taukid atas klaim kecantikan Zulaikha. ${ }^{44}$ Dalam ayat 25 dari surah Yusuf ini, Moh. E Hasim dengan brilian menggunakan secara tepat paribasa untuk menggambarkan dialog antara Zulaikha dangan suaminya di saat ketahuan hendak mengejar-ngejar Yusuf. ${ }^{45}$

Paribasa yang dipakai oleh Zulaikha untuk menguatkan klaimnya bahwa Yusuf telah memaksa berbuat tidak senonoh dengan dirinya adalah pindah peleumpangeun dan melengkung bekas nyalahan. Dalam kamus peribahasa sunda, pindah peleumpangeun artinya berubah sifat karena merasa naik derajat. $^{46}$ Adapaun melengkung bekas nayalahan artinya seperti yang baik hati, namun lama-lama menjadi jahat. ${ }^{47}$ Ketika Muda baik hati, namun ketika sudah dewasa tidak lagi baik mengaitkannya dengan kekuatan bahasa Arab Alquran yang mampu menyentuh siapapun yang membacanya. Bahasa Alquran sangat indah dalam balutan sastra. Untuk itulah, tanpa bermaksud

mentrangan, halisna ngajeler paeh, irungna kuwungkuwungan. Ari imut matak ngirut, matak deungdeuleueun anu neuteup." Moh. Hasim. Ayat Suci Leunyepaneun, Juz. 12, 237.

${ }^{44}$ Ini semua adalah penggambaran wanita cantik bagi orang Sunda. Babasan yang dipakai menunjukkan kesempurnaan tubuh Zulaikha. Dari mulai mata, hidung, muka, alis, semuanya menujukkan kesempurnaan. Konsepsi kecantikan Zulaikha dijabarkan melalui konespsi kecantikan dalam standar orang Sunda. Penggunaan babasan di atas berfungsi untuk menguatkan keterangan yang hendak disampaikan seputar kecantikan Zulaikha.

${ }^{45}$ Hasim menulis:" Numawi Yusuf teh saparantos dewasa mah pindah peleumpangeun melengkung bekas nayalahan, maksa ngalakukeun serong ka abdi. Ayeuna mah nyanggakeun ka pangersa, abdi mah malik teu suka sareng bakal nyungkelik salamina upama manehna henteu kabuikeun atawa dihukum ku siksaan nu pikanyerieun.”Moh. Hasim. Ayat Suci Leunyepaneun, Juz. 12, 241.

${ }^{46}$ Ajip Rosidi, Babasan, 135.

${ }^{47} \mathrm{~T}$. Fatimah dkk, 110. menjadikan tulisannya sejajar dengan Alquran, Hasim mencoba menulis karyanya dengan nuansa sastra agar terasa indah bagi pembacanya.

\section{SIMPULAN}

Penelitian ini membuktikan bahwa Moh.

E. Hasim dan tafsirnya, Ayat Suci Lenyepaneun, berhasil membangun blok baru penafsiran Alquran yang ada selama ini. Sementara ini, karya-karya tafsir selalu keluar dari kelompok agamis yang pernah mengenyam pendidikan agama, baik di pesantren, masjid, maupun perguruan tinggi lainnya. Setidaknya, dari literatur kajian Alquran di tanah Sunda, baik tafsir maupun terjemahan, lahir dari tokoh-tokoh berpendidikan agama maupun pendidikan formal. Mereka pernah mengenyam pendidikan pesantren, perguruan tinggi Islam. Berbeda dengan Hasim yang membuat tafsir Ayat Suci Lenyepaneun dia adalah sang mufasir yang hanya pensiunan tentara, dia bukan seorang akademis maupun budayawan Sunda. Akan tetapi dia mampu memberikan karya yang unik dan patut untuk dikaji lebih dalam baik dari segi tafsirannya maupun budaya Sunda yang tercatat dan disajikan Hasim dalam tafsirannya. Sehingga penulis tertarik untuk meneliti kajian ini dan mendapatkan kesimpulan dari hasil penelitian ini, diantaranya: Penafsiran Moh. E. Hasim dalam tafsir Ayat Suci Lenyepaneun mengenai karakter perempuan dalam Alquran yang terdapat pada ayat-ayat berikut: (1). QS. AlTahrim [66]: 11, (2). QS. Maryam [19]: 17-19, (3). QS. Al-Lahab [111]: 4-5, (4). QS. AlTahrim [66]: 10, (5). QS. Yusūf [12]: 23 menunjukan Lima karakter perempuan yaitu: (1) karakter perempuan dengan kepribadian kuat, (2) karakter perempuan yang menjaga kesuciannya, (3) karakter perempuan penghasut, (4) karater perempuan pembangkang kepada suaminya, dan (5) karakter perempuan penggoda. 
Nadia Laraswati, Syahrullah dan Ahmad Gibson Al-Bustomi

\section{DAFTAR PUSTAKA}

Djajasudarma, T Fatimah, dkk. Nilai Budaya Dalam Ungkapan dan Peribahasa Sunda. Cet.1. Jakarta: Depdikbud, 1997.

Federspiel, Howard M.Kajian al-Quran di Indonesia: dari M. Yunus hingga Quraish Shihab. terj. Tajul. Bandung: Mizan, 1994.

Gusmian, Islah.Khazanah Tafsir Indonesia; dari Hermeneutika hingga Ideologi.Cet. I.Jakarta: Teraju, 2003.

Hasim, Moh E.Ayat Suci Lenyepaneun.cet. II. Bandung: Pustaka, 1999.

Hidayat,Rahmat Taufiq,dkk.Peperenian Urang Sunda. Bandung: Kiblat, 2005.

Jaques,R. Kevin.Islamicate Society, dalam Richard C. Martin, Encyclopaedia of Islam and the Muslim World. Vol. 1.New York: Macmillan, 2004.
Karakteristik kebahasaan Tafsir Ayat Suci Lenyepaneun Karya Moh.E.Hasim (Analisis Terhadap Karakter

Perempuan Dalam Alquran)

Rosidi, Ajip. Sastra dan Budaya.Cet. 1. Jakarta: Pustaka Jaya, 1995.

Sugono,Dendy.KBBI. Jakarta: Pusat Bahasa, 2004.

Sumaryono, E. Hermeneutik. Yogyakarta: t.p, 1984.

Yusuf,Muhammad.Perkembangan Tafsir alQur'an di Sulawesi Selatan: Studi Kritis Tafsîr Al-Qur'ân al-Karîm Mabbasa Ogi "karya Anre Gurutta (selanjutnya: AG.) H. Abd. Muin Yusuf dkk. Jurnal Bimas Islam. Vo. 2. No. 1. 2009.

Zimmer, Benjamin G. Al-'Arabiyyah and Basa Sunda: Ideologies of Translation and Interpretation among the Muslims of West Java. Studia Islamika. 7 (3): 2000. 